tabercle gave a slight positive result. During the first week his temperature ranged from $98^{\circ}$ to $101^{\circ} \mathrm{F}$., but for the last five weeks it was rarely above normal; the pulse was about 80 and the respirations 20 to 30 .

Two points are of interest in the present case and demand an explanation, first, the occurrence of pneumothorax in a patient without obvious cause, and, secondly, the presence of blood along with the pneumothorax apart froth injury.

Of all causes of pneumothorax, phthisis is, of course, much the commonest; of 918 cases compiled by Biach ${ }^{1}$ from thixty.eight years' records of three Vienna hospitals it was the cause in 715 , or 77.8 per cent. Gangrene, empyema, injury, bronchiectasis, and emphysema came next in order, while 14, or 1.5 per cent., are noted as due to uncertain causes. Hall ${ }^{2}$ in 1887 collected 31 cases of pneumothorax occurring in the apparently healthy, including 21 previously noted by West; he found a strain of some kind to be the chief exciting cause, and that even if serous effusion followed, recovery in from five to six weeks was the rule. Hremothorax (that is, effusion of blood and not simply blood-stained fluid), on the other hand, is usually due to trauma or rupture of thoracic aneurysm, while tubercle and malignant disease figure as other possible causes.

Finlay ${ }^{3}$ states that, apart from injury, haemopneumothorax is extremely rare, and that the cause is altogether obscure. He refers to two cases which may be briefly noted.

Pitt ${ }^{4}$ in 1900 made a communication to the Clinical Society of London "on a rapidly fatal case of haemopneumothorax apparently due to rupture of an emphysematous bulla." The patient was a youth, aged 18 years, who was attacked with pain when taking a walk and died next day. At the autopsy the pleural cavity was found to contein 8 pints of fluid blood and clot enough to fill the haids three times. Near the apex of the lung a ruptured emphysematous bulla was found, quite sufficient to account for the air, but no evident cause for the blood could be found, unless it came from an adhesion which extended from the bulla to the pleura, and which had been torn across. No aneurysmal dilatation or patent vessel could, however, be seen. There was no trace of tubercle, either recent or old. At that,time he examined the records, and could find no definite case of haemopneumothorax, apart trom injury, save one case in the Guy's Hospital Reports, dtie to rupture of an aneurysm in a large phthisical carity. He remarks, incidentally, on the rapidity with which the pleura can deel with effused blood, and also on its power of keeping the blood fluid, though not necessarily unaltered, espocially in non-traumatic cases.

It is to be noted in this connexion that the fluid drawn off from this patient showed no tendency to clot, though it was kept for many days.

Shortly afterwards Rollestions reported to the same society "a cate of fatel hremopneumothorax of unexpleined origin" occarring in a youth aged 21 , who died in six days. There had been no injury and no previous pulmonary symptoms: At the autopsy $60 \mathrm{oz}$. of fluid blood and a few ounces of clot were present in the plearal cavity, bat no cause for either the blood or air could be found, although carefal search was made. The possibility of the blood being due to some hasmophilic condition was considered, although there were no grounds for the assumption, and the question was even eaised whether the air might not have been derived from the blood by irregular respiratory movements causing a negative intrapteciral pressure: The etiology, however, cemained quite unexplăined.

We have been unable to trace any case at all compatable occuriving since these two, and while both of those were examined post mortem, the findings do not warrant us' in asriving at any definite conclusion as to the carstition of the now reported, and one gets little or no guide from the ordinary conditions accepted as causes of pneumothorax. It must therefore be classified for the present as a case of haemepneumothorax of unexplained origin occurring in the apparently healthy.

1 Biach : Quoted by Finlay, System of II

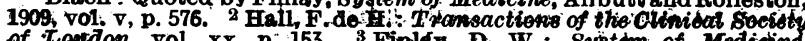
of Tootdon. vol. xx, p. 153. 3 Findy. D. W.: System of Medictind, of this Clinicat Society of London, vol. Xxxii, p. 95 . ' Rolleston, $\mathrm{H}$. D. : Iransactions of the Clinical Society of London, vol, xxxiii, p. 90 .

\section{A CASE OF}

ACUTE TUBERCULOUS BRONCHO-PNEUMONIA AFTER GASTRO-ENTEROSTOMY.

BY

W. A. MACKAY, M.D.ED., IAN MACDONALD,M.D.ED, F.R.C.S.E.,

CONSULTING SERGEON TO THF RIO TINTO CO. M.D.PARIS,

CONSULTING SURGEON TO THI UNITED ALKAII AND PENA

AND

HALLIDAY G. SUTHERLAND, M.D.ED., MEDICAL SUPERINTENDENT, THE WESTMORLAND SANATORIUM.

THE pulmonary complications after gastro-enterostomy are practically the only immediate dangers to be feared since the disappearance of the vicious circle, and their cause is as jet uncertain, but it seems to be generally admitted that they are most frequent after operations on the gastro-intestinal tract. By careful disinfection of the mouth for some days prior to operation, by avoidance of chill during the preparation of the patient, by the minimum exposure of the viscera, and by the adoption of the elevated position whenever the effects of the anaesthetic have worn off, much can be done to shield the patient from the onset of pulmonary complications.

In a first series of 80 gastro-enterostomies, including cancer cases, we have lost 2 patients-one from vicious circle, the other, a man of 60 , from pneumonia. The following case is of interest from the specific variety of broncho-pneumonia which supervened, causing the death of the patient six months later.

A farm labourer, aged 39, complained of chronic indigestion, attended by severe epigastric pain without vomiting, usually most severe in the early hours of the morning.

\section{HISTORY.}

The condition had existed for fourteen years, and during the last year the patient had lost weight, and the nocturnal pain was at times so acute that he would pass the night rolling about doubled up in bed. Towards morning the pain became easier, and almost disappeared when he rose at 7 a.m. At 8 a.m. he was accustomed to take a cup of coffee, and an hour later the pain would return more or less continuously until mid-day, when he ate again and felt relieved, only to suffer another attack at 3 or 4 p.m. His next meal was at 6 p.m., after which he immediately felt better, but at midnight the onset of pain would awaken him. He had been in the habit of taking a herb tea in the night which gave relief, and occasionally sodium bicarbonste. The pain was situated in the medisn line in the epigastrium, and radiated round both sides of the thorax and through to the back. He had no vomiting, unless voluntarily induced, which he did from time to time to empty the stomach and so ease the pain, but he had constant eructations, and an acid teste in his mouth. He would pass three or four days without a motion, and said that on two or three occasions he had passed black motions. He was always worse in cold had passed black motions. He was always worse in cold diagnosis of duodenal ulcer was made, and confirmed by a test meal, which showed no stasis but considerable hyperacidity.

\section{Operation.}

He was admitted to the Clinque Mackay, Huelva, Spain, on January 17th, 1908. The chest was carefully examined and found to show no abnormality, nor was there any history of any chest trouble; the morning and evening temperatures were normal, and the heart and kidneys were sound. Careful disinfection of the mouth was carried out up to the 'day of opera: tion. On the day before operation the patient was in great pain, and vomited some of the milk on which he was fed for twenty-four hours before operation.

On January 22nd, after five days' observation, the abdomen was opened above and to the right of the umbilicus by pulling the right rectus outwards. On inspection of the pylorus nothing abnormal was seen, but about 1 in. beyond the pyloric venons plexus on the upper surface of the duodenum an irregularly ronnded ulcer, the size of a sixpence, with a hard, indurated base, was easily demonstrated to the onlookers. Posterior gastro-enterostomy, with clamps and suture, was perform'ed and the patient put back to bed in good condition.

\section{Acute Tuberculous Broncho-Pneumonia.} (Remarks by Dr. Sutherland.)

During the first five days following the operation the patient's general condition was good, although he had slight cough and spatum which was attributed to the chloroform. Examination of the chest on the fifth day disclosed neither alterations in the breath sounds nor accompaniments, while the temperature doring this period only showed the usual post-operative rise.

The six th day, however, marked the onset of acute tuberculous broncho-preumonia. The evening temperature ndade' a sudden rise from $99^{\circ} \mathrm{F}$. to $102^{\circ} \mathrm{F}$., while anscultation revealed the general signs of bronchitis, which altered at the end of the week to those of broncho-pneumonia; that is to say, the rhonchi 
disappeared and the breath sounds were diminished over both lungs, with the exception of the lower right lobe and the upper left lobe, where the breathing was broncho-vesicular, with moist râles on inspiration, and here and there an area of increased vocal resonance. The percussion note was slightly dulled over the left apex, where "tidal percussion" revealed diminished expansion. He was given benzoin inhalations and 6 grains of quinine thrice a day, in the hope that there might be an element of malaria in his condition. Daring this week he complained of malaria in his condition. During this week he com

of profase sweats at night and diarrhoea commenced.
During the second week he complained of sharp pain in the right side, where friction was frequent, and the breath sounds underwent further modification. The breathing was harsh and broncho-vesicular all over the chest, with copious musical rhonchi both on inspiration and expiration. Here and there over all lobes were patches, showing bronchial breathing and increased vocal resonance, whilo the "tidal percussion" showed no expansion at either apex or at the bases behind, where dry inspiratory clicks during inspiration were heard. The sputum contained tubercle bacilli and elastic tissue, but was not copious. After the initial rise, the temperatqre remained continuously high, between $101^{\circ}$ and $102^{\circ} \mathrm{F}$., with an absence of remissions. The pulse, following the temperature, showed no remissions, and during the first two weeks averaged 80 , but during the third week rose to an average of 94. Respirations ranged between 22 and 24 .

It is obvious that in this case we were dealing with the comparatively rare condition in the adult of acute tuberculous bronchopneumonia. Prior to the operation the patient had neither cough nor sputum, while a careful examination revealed no abnormality of the chest. Further, the patient denied the slightest sign of chest disease prior to the present illness, and the family history was good. At the same time, it is probable that he bad a latent focus of infection, which only required a lowered resistance to break out into this grave form of phthisis. When we recall the fact that 90 per cent. of normal

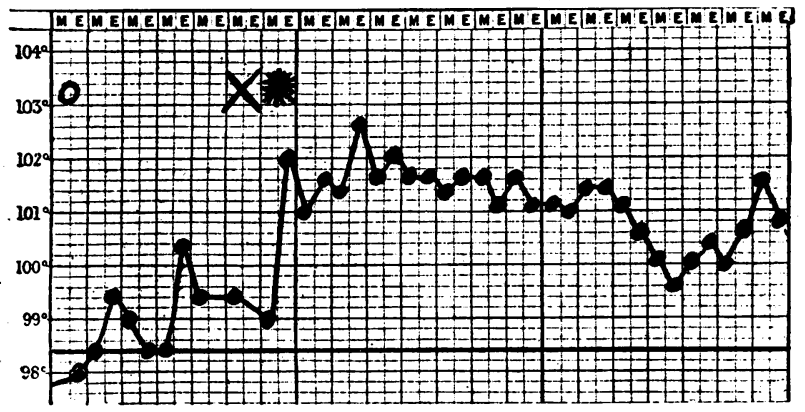

u, Oparation: $\mathrm{x}$, chcst examined, nil ; $*$ onset of acute tuberculous bronchopneumonia.

persons have had, at one time or another, some focus of infection in the lungs, the etiology of the case is not obscure. In spite of the long period of disturbed nutrition consequent on the intestinal lesion, this patient presented sufficient resistance to hold the disease in check until some condition so weakened the pulmonary resistance that in $t w 0$ weeks the two lungs were infected in every lobe.

Since the operation of gastro enterostomy has come to be one of the most frequent in abdominal surgery, it has been generally recognized, especially on the Continent, that the danger of the operation itself is nothing compared to the risk of post-operative pulmonary infection, which usually takes the form of bronchopneumonia. In view of the bovine and ingestion theory of tubercu. lous infection, there is no doubt that the long period of intestinal disease would predispose to the entrance of the tubercle bacillus into the system, but any suspicion of the duodenal ulcer being tuberculous was negatived by the clinical history of the case; the appearance of the ulcer at operation, and a negative result in examining the faeces for tubercle bacilli. The patient died in six months from this acute form of pulmonary tuberculosis. Relief from gastric symptoms was complete.

The incidence of phthisis supervening on chronic gastric or duodenal ulcer is given by different authorities at 20 to 27 per cent. of the complications of the gastric or intestinal lesion; and, in view of the fact experimentally proved that a lesion of the intestinal tract favours the absorption of tubercle bacilli into the lymph. atic and circulatory systems, by either of which routes they may reach the lung, there is a clear indication for the earlier resort to surgical measures in cases of chronic ulcers which are not benefited by medical treatment.

\section{A TYPHOID CARRIER.}

BY

J. R. HUTCHINSON, M.B., D.P.H.,

ASSISTANT TO THE MEDICAL OFFICER OF HEALTH, MANCHESTER.

The circumstances of this case are briefly as follows:

J. H. W., aged 36, commenced with enteric fever on or about September 24th, 1908. Widal's test was positive on October 19th 1908. This patient had been living at the house in which he then was for four days. Prior to this he had lodged for some months at the house of a Mrs. W., a widow, who gets her living by taking in lodgers. She does all her own housework, and commonly has two or three lodgers.

At the same house in which J. H. W. was presumably infected, three previous cases (II, III, and IV) of enteric fever had occurred amongst Mrs. W.'s lodgers.

CASE II (130, 1907).

J. W. E., aged 19, commenced to be ill on September 7th, 1907. On September 28th he was removed to the fever hospital. His blood gave a positive reaction. He recovered.

\section{CASE III $(224,1906)$}

A. A., aged 28, commenced to be ill on September 4th, 1906 . His blool gave a positive reaction. Death occurred on October 16th, 1906.

CASE IV $(135,1906)$.

A. W., aged 28, commenced to be ill on May 2nd, 1906. His blood gave a positive reaction. Death took place on June 14th, 1906.

All these four cases were infected between May, 1906, and September, 1908, at the one house kept by Mrs. W. during this period. Three further cases were traced to two other houses at which Mrs. W. had previously taken in lodgers.

CASE v $(174,1905)$.

H. R., aged 19. Onset of disease, May 20th, 1905. Blood reaction positive. There is just a chance that this patient was
infected outside Manchester, but this is unlikely. He had lodged at this house for three months.

CASE vi (118, 1905).

H. P., aged 25. Onset, April 8th, 1905. Blood reaction posi tive. A daughter of $H$. P.'s too had a prolonged febrile illness about this time; the details of this illness are not forthcoming; a blood specimen could not be obtained. Both father and daughter were lodgers with Mrs. W.

\section{Case VII (388, 1898).}

W. D., aged 23. Onset, October 4th, 1898. Removed to the fever hospital, and died November lst, 1898. For six weeks prior to October 4th W. D. had lodged with Mrs. W:

The only factor common to all these cases is the presence of Mrs. W. No history of contact with known enteric fever cases, or of consumption of food likely to be infected, was obtainable in any of these cases.

Mrs. W.'s medical history is as follows: Up to 1893, when she was about 54 years old, she enjoyed good health, and never had occasion to see a medical man. In this year she had an attack of "influenza and pneumonia," for which she was treated in a union hospital. She remembers little about this illness except that she had severe headaches and pains in the back, and was delirious. She was ill for five weeks, and was fed entirely on fluid foods. Since this illness she has suffered from periodic attacks of abdominal pain and vomiting. These attacks did not follow immediately on the illness of 1893 ; there was an interval of five years during which her health was good. A specimen of blood obtained in November, 1907, gave a negative reaction.

Five of the seven cases recorded above are also recorded in the annual report of the medical officer of health for Manchester for 1907. The occurrence of a sixth case in September, 1908, caused further search to be made, when a seventh was discovered so far back as 1898.

No cases can be found as having occurred at the house of Mrs. W. prior to 1898. Possibly some may have been overlooked. It was not until 1898 that Mrs. $\mathrm{W}$. began to suffer from attacks of abdominal pain and vomiting after her five years of good health. The year she began to be ill was marked by the appearance of the first known. case of enteric fever amongst her lodgers. There is no. doubt that she was ill before her lodger.

It is curious that no further cases should come to light between 1898 and 1905; certainly none were notified during this period. It is a well.known fact that in "carrier." cases the bacilli are excreted in the stools and urine in batches with bacillus-free intervals. Many such batches must have been shed from time to time during these years. In October, 1908, Mrs. W. was examined by 